\title{
Electrocardiograms and 13 year cardiovascular mortality in Busselton study
}

\author{
KEVIN CULLEN, N S STENHOUSE, K L WEARNE, G N CUMPSTON \\ From Busselton Health Centre, Mill Road, Busselton; Raine Medical Statistics Unit, University of Western \\ Australia, Nedlands; and Department of Cardiology, Royal Perth Hospital, Perth, Western Australia
}

SUMMARY In 2119 unselected Busselton subjects 40 to 79 years of age, the 13 year mortality from cardiovascular disease was significantly higher in those whose initial electrocardiogram showed $Q$ and QS patterns, left axis deviation, ST depression, $T$ wave depression, flat or biphasic $T$ waves, atrial fibrillation or flutter, and ventricular extrasystoles.

In angina-free subjects whose electrocardiographic codes occurred in isolation from any other electrocardiographic abnormality, ventricular extrasystoles were associated with significantly higher mortality from cardiovascular disease compared with controls.

Since 1966, the Busselton population has been the subject of a longitudinal study of cardiovascular mortality. ${ }^{1}$ Resting electrocardiograms were associated with significantly increased six year mortality in those with suspected ischaemic heart disease, and in those with probable ischaemic heart disease to factors of seven to nine times and 20 times, respectively. ${ }^{2}$ The present paper outlines the 13 year cardiovascular mortality in 2119 unselected subjects 40 to 79 years of age, related to their electrocardiograms recorded in 1966.

\section{Methods}

Resting electrocardiograms were recorded on Nihon Kohden machines, model MC-11 and Model MC-3, with a paper speed of $25 \mathrm{~mm}$ per second. These machines fulfilled the performance recommendations of the AHA Committee on Electrocardiography $1967^{3}$ except in the high frequency range, where constant amplitude sinusoidal input signals of $100 \mathrm{~Hz}$ were reduced to $50 \%$. The maximum reduction should be no more than $30 \%$. Such a defect could in part affect the prevalence of tall $R$ waves. There were no specific intervals between the time of the meal and recording of the electrocardiograms, but approximately $10 \%$ of -subjects had their electrocardiograms recorded about one and a quarter hours after a $50 \mathrm{~g}$ glucose drink. For the remaining subjects, there was a longer interval.

All electrocardiograms have been classified according to the Minnesota Code ${ }^{4}$ by five trained observers

Accepted for publication 24 August 1981 working independently under the guidance of a consultant cardiologist (GNC). All subjects answered the chest pain questionnaire of Rose. ${ }^{5}$

One thousand and fifty-six men and 1063 women were studied. Mortality in this group between January 1967 to December 1979 was confirmed by the Registrar of Deaths in Perth, Western Australia. Survivor status was established by local contact and by checking all compulsory electoral rolls in Western Australia. Twenty-one men and 18 women could not be traced. All missing subjects were checked against the Registrar's files for possible deaths. The ICD 8th revision (1968) codes used to determine mortality resulting from cardiovascular disease were $390-458$ and 746-747. The 13 year cardiovascular disease mortality in control subjects with a normal electrocardiogram was compared in each instance with the cardiovascular disease mortality of those found with the specified abnormality.

Using the total 40 to 79 year population as a basis, standardised mortality rates for specific electrocardiographic codes and for the "normal electrocardiogram" population were calculated by the direct method. ${ }^{6}$ The standardised mortality rate for the "normal electrocardiogram" population was compared with that for the population with a specific electrocardiographic code, expressed first as a difference and second as a ratio. The difference was used to calculate an approximate standardised normal deviate, and the appropriate test of significance performed.

Initially, all populations were divided into eight five-year age groups, for each sex. It was decided to standardise using only those age-groups where the 
Table Thirteen year cardiovascular mortality in 2119 subjects for specific electrocardiographic codes compared with populatioñ ? Specific code

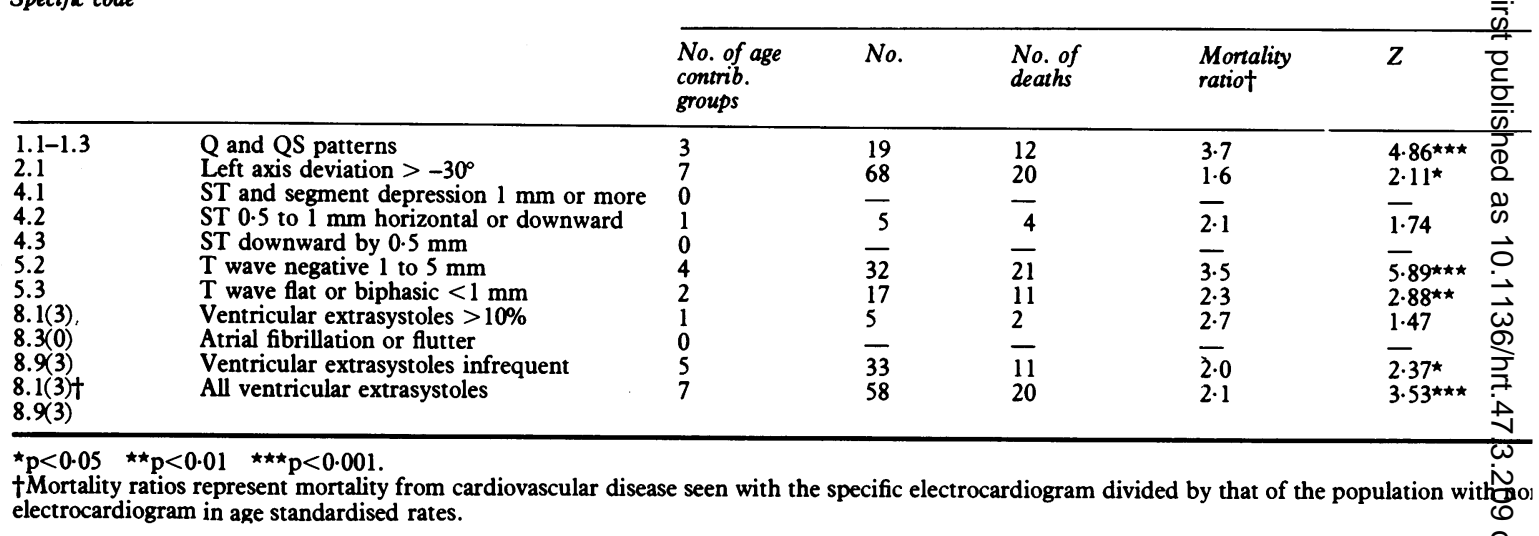

specific electrocardiographic code population had at least five people at risk. In this data set all eight age groups were used in calculating rates and ratios on only four occasions, and then only when the sexes were combined.

Finally, two different methods of determining the specific electrocardiographic code populations were used-firstly, where the particular code existed without regard to any other code that may have been present: these results are presented in the Table for the 2119 unselected subjects aged 40 to 79 years. The second method analysed the mortality in 1497 subjects free of angina for each electrocardiographic code in isolation from any other code.

\section{Results}

The Table outlines the findings in the 2119 unselected subjects aged 40 to 79 years. Mortality from cardiovascular disease was significantly higher in those whose initial electrocardiogram showed Q-QS patterns, left axis deviation, ST junction and ST segment depression, negative $T$ waves, flat or biphasic $T$ waves, atrial fibrillation or flutter, ventricular extrasystoles more than $10 \%$ of all complexes, and infrequent ventricular extrasystoles.

In 1497 subjects free of angina, the analysis of those electrocardiographic codes without any other coexisting electrocardiographic codes (not tabled with the results of the unselected subjects in the Table) has shown that infrequent ventricular extrasystoles were the only electrocardiographic code in isolation to be associated with a raised risk of cardiovascular disease. The mortality ratio was 2.1 for both sexes in six contributing age groups, with 11 deaths in 46 subjects with a $Z$ value of $2.55(p<0.05)$. The cardiovascular disease mortality ratio for all types of ventricular extrasystoles was 2.4 for both sexes, with a $Z$ value of $3.44(\mathrm{p}<0.001)$ in seven contributing age groups, showing 15 deaths in 61 subjects.

\section{Discussion}

\section{VENTRICULAR EXTRASYSTOLES}

A recent review ${ }^{7}$ concluded that ventricular extrasystoles occurring in subjects without clinical evidence of $\stackrel{\odot}{\unrhd}$ cardiac disease appear not to be associated with an $\overrightarrow{\overrightarrow{0}}$ increased incidence of either sudden death or death. In contrast to these conclusions, Blackburn et al. ${ }^{8} \rightleftharpoons$ reported an increased incidence of coronary heart disease in those with ventricular extrasystoles compared with carefully matched controls. The ratio of expected to observed was 1.9 , the number being too small to reach levels of significance. These findings resembled those in Busselton where ventricular extrasystoles in angina-free individuals without coexisting electrocardiographic abnormalities were associated with a significant increase in mortality from cardiovascular disease.

Q AND QS, T WAVE CHANGES, AND ATRIAL FIBRILLATION

In Busselton unselected subjects, $Q$ and $Q S$ changes, $\mathrm{N}$ ST segment and $T$ wave changes, atrial fibrillation, $\omega$ and left axis deviation were associated with significantly greater mortality from cardiovascular disease. The numbers showing these abnormalities in selected subjects were too small to be of significance.

In 18403 unselected civil servants 40 to 64 years, $\frac{T}{O}$ Rose et al. ${ }^{9}$ reported significantly increased coronary $\overrightarrow{\mathbb{D}}$ heart disease mortality in those with small $Q$ waves, $\frac{O}{\mathbb{D}}$ left axis deviation, flat or inverted $T$ waves, and left $\varrho$ 
mal electrocardiograms each standardised in five year age groups for Busselton population 40 to 79 years

\begin{tabular}{|c|c|c|c|c|c|c|c|c|c|}
\hline \multicolumn{5}{|l|}{ nen } & \multicolumn{5}{|l|}{ All subjects } \\
\hline $\begin{array}{l}\text { of age } \\
\text { rib. } \\
\text { ps }\end{array}$ & No. & $\begin{array}{l}\text { No. of } \\
\text { deaths }\end{array}$ & $\begin{array}{l}\text { Mortality } \\
\text { ratio }\end{array}$ & $Z$ & $\begin{array}{l}\text { No. of age } \\
\text { contrib. } \\
\text { groups }\end{array}$ & $\begin{array}{l}\text { No. of all } \\
\text { subjects }\end{array}$ & $\begin{array}{l}\text { No. of } \\
\text { deaths }\end{array}$ & $\begin{array}{l}\text { Mortality } \\
\text { ratio }\end{array}$ & $Z$ \\
\hline . & $\begin{array}{r}12 \\
41 \\
-6 \\
19 \\
39 \\
33 \\
- \\
- \\
32 \\
34\end{array}$ & $\begin{array}{r}7 \\
12 \\
3 \\
11 \\
29 \\
14 \\
- \\
12 \\
14\end{array}$ & $\begin{array}{l}2 \cdot 1 \\
2 \cdot 1 \\
\overline{2 \cdot 2} \\
3 \cdot 0 \\
5 \cdot 2 \\
3 \cdot 0 \\
- \\
- \\
2.7 \\
3 \cdot 0\end{array}$ & $\begin{array}{l}1 \cdot 9 \\
2 \cdot 42^{\star} \\
- \\
1 \cdot 43 \\
3 \cdot 06^{\star \star} \\
8 \cdot 43^{\star \star \star} \\
4 \cdot 03^{\star \star \star} \\
- \\
\overline{3} \cdot 40^{\star \star \star} \\
4 \cdot 02^{\star \star \star}\end{array}$ & $\begin{array}{l}7 \\
8 \\
3 \\
5 \\
6 \\
6 \\
7 \\
2 \\
1 \\
8 \\
8\end{array}$ & $\begin{array}{r}58 \\
119 \\
20 \\
37 \\
51 \\
79 \\
69 \\
10 \\
5 \\
84 \\
106\end{array}$ & $\begin{array}{r}29 \\
32 \\
15 \\
18 \\
26 \\
53 \\
31 \\
4 \\
4 \\
25 \\
35\end{array}$ & $\begin{array}{l}3.82 \\
1.64 \\
3.82 \\
2.81 \\
2.81 \\
4.5 \\
3.3 \\
2.8 \\
2.4 \\
2.2 \\
2.6\end{array}$ & $\begin{array}{c}7.60^{\star \star \star} \\
2.461^{\star} \\
5.53^{\star \star \star} \\
4.69^{\star \star \star} \\
5.14^{\star \star \star} \\
11.07^{\star \star \star} \\
6.64^{\star \star \star} \\
2.29^{\star \star \star} \\
2.04^{\star} \\
3.93^{\star \star \star} \\
5.62^{\star \star \star}\end{array}$ \\
\hline
\end{tabular}

bundle-branch block. In symptomless normotensive subjects, only those with prominent $Q$ waves and atrial fibrillation showed excess mortality from coronary heart disease.

In an international study ${ }^{8}$ of 12770 men of 40 to 59 years, there was a significantly increased five year incidence of coronary heart disease in those with major $Q$ and $Q S$ complexes, with negative $T$ waves, and in those with atrial fibrillation compared with carefully matched control subjects. An increased risk of stroke from emboli was reported ${ }^{10}$ in Framingham subjects with atrial fibrillation.

\section{LEFT VENTRICULAR HYPERTROPHY}

An increased cardiovascular disease mortality has been described ${ }^{11}$ in those with left ventricular hypertrophy, compared with the population at large. In Busselton, left ventricular hypertrophy was not associated with significantly increased cardiovascular mortality.

\section{LEFT BUNDLE-BRANCH BLOCK AND RIGHT BUNDLE-BRANCH BLOCK}

Schneider et al. ${ }^{12}$ have recently reported that $50 \%$ of 55 Framingham subjects with left bundle-branch block had died within 10 years of its onset with only $11 \%$ remaining clinically free of cardiovascular abnormalities. The mean age of onset for left bundle-branch block was 62 years. Schneider et al. ${ }^{13}$ also reported on newly acquired right bundle-branch block in 70 Framingham subjects over a period of 18 years, mortality from cardiovascular disease being almost three times greater in these subjects than in an age matched sample of the population at large. Busselton subjects showed no significant increase in cardiovascular disease mortality for left and right bundle-branch block in the analysis of age specific mortality.
The Busselton Population Study has been supported by the University of Western Australia, the Arnold Yeldam and Mary Raine Medical Research Foundation, the National Heart Foundation, the Royal Perth Hospital, State Health Laboratories (WA), and the National Health and Medical Research Foundation, Telethon(WA).

\section{References}

1 Curnow DH, Cullen KJ, McCall MG, Stenhouse NS, Welborn TA. Health and disease in a rural community. A Western Australia study. Aust f Sci 1969; 31: 281-5.

2 Cullen KJ, Murphy BP, Cumpston GN. Electrocardiograms in the Busselton population. Aust NZ F Med 1974; 4: $325-30$.

3 American Heart Association. Committee on Electrocardiography. Recommendations for standardization of leads and specifications for instruments in electrocardiography and vectorcardiography. Circulation 1967; 35: 583-602.

4 Rose G, Blackburn H. Cardiovascular survey methods. WHO Monogr Ser 1968; No. 56.

5 Rose GA. Chest pain questionnaire. Milbank Mem Fund $Q$ 1965; 43 (Part 2): 32-9.

6 Armitage P. Statistical methods in medical research. Oxford: Blackwell Scientific Publications, 1971: 387.

7 Barrett PA, Peter CT, Swan HJC, Singh BN, Mandel WJ. The frequency and prognostic significance of electrocardiographic abnormalities in clinically normal individuals. Prog Cardiovasc Dis 1981; 28: 299-319.

8 Blackburn H, Taylor HL, Keys A. Coronary heart disease in seven countries XVI. The electrocardiogram in prediction of five year coronary heart disease incidence among men aged forty through fifty-nine. Circulation 1970; 41, suppl 1: 154-61.

9 Rose G, Baxter PJ, Reid DD, McCartney P. Prevalence and prognosis of electrocardiographic findings in middle aged men. Br Heart $\mathcal{F}$ 1978; 40: 636-43.

10 Wolf PA, Dawber TR, Thomas HE Jr, Kannel WB. Epidemiologic assessment of chronic atrial fibrillation 
and risk of stroke. The Framingham study. Neurology (Minneap) 1978; 28: 973-7.

11 Kannel WB, Gordon T, Offutt D. Left ventricular hypertrophy by electrocardiogram. Ann Intern Med 1969; 71: 89-105.

12 Schneider JF, Thomas HE Jr, Kreger BE, McNamara PM, Kannel WB. Newly acquired left bundle-branch block; the Framingham study. Ann Intern Med 1979; 90: 303-10.
Cullen, Stenhouse, Wearne, Cumpston

13 Schneider JF, Thomas HE Jr, Kreger BE, McNamara PM, Sorlie P, Kannel WB. Newly acquired right bundle-branch block. Ann Intern Med 1980; 92: 37-44.

Requests for reprints to Dr Kevin Cullen, Busselton Health Centre, Mill Road, Busselton, Western Australia 6280. 